\title{
Research Reports on Initial Public Offerings (IPOs): Analysis of Target Stock Price Accuracy
}

\author{
Andrew J. Sherbo, Ryan Finn \\ Daniels College of Business University of Denver, Denver, CO, United States \\ Email: asherbo@du.edu
}

\begin{abstract}
Research Reports on Initial Public Offerings (IPOs) offer analysts with unique challenges. There is little, if any, financial background on the corporation and these Reports can be very influential as the company goes public for the first time. We examined 692 Research Reports issued on nearly 200 IPO's during 2013 and found their Target Stock Price (TSP) accuracy to be very respectable when compared to Reports issued on mature companies. We looked at IPO Reports issued by at least one analyst with a Chartered Financial Analyst $\left(\mathrm{CFA}^{\circledR}\right)$ designation. These results showed a slightly higher, accuracy rate than reports issued by non-CFA analyst(s). Finally, we ranked twelve securities firms on their TSP accuracy rates.
\end{abstract}

Keywords: Initial public offerings; research reports

\section{Introduction}

Research Reports are an important product produced by many firms in the securities business. They are written on corporations as old as General Electric founded in 1892, and on new companies going public for the first time in an Initial Public Offering (IPO) such as Snap, Inc., in 2017 (NYSE: SNAP). This article focuses on the latter as we wanted to look at the Target Stock Price (TSP) accuracy of what we view as probably the toughest Research Report to write, a corporation with basically no previous track record on the valuation or the performance of its stock price. The TSP is important because it leads to a Buy, Sell, or Hold recommendation when compared to the current stock price. This article begins with a review of the literature on the topic of TSP or Analyst Accuracy. It is important to immediately note that we found no such prior research exists on testing such accuracy with Research Reports on IPOs. The article then turns to the methodology and database, reports results, and presents our conclusions on what we believe to be the first research of its kind on Research Reports and IPOs.

\section{Review of Recent Research}

We thought regular analysis on the accuracy of Research Reports would be quite plentiful. We were mistaken. After all, such Reports are making very specific recommendations (e.g., Buy, Sell, Hold) and normally provide a specific TSP. The TSP tells the investor how much of an annual gain can be expected in the stock price. If the current stock price is $\$ 40$ per share and the TSP is $\$ 50$ within twelve months (the normal timeframe in Research Reports), then the annual expected gain would be $25 \%$. This percentage would be compared against alternative investments at the same and different levels of risk. Moreover, investors often compare the expected TSP gain against the expected gain using an index (passive) strategy such as investing in the S\&P 500 over the same period. Research Reports are a form of active investing advice because if the predicted returns are less than what the investor expects from the S\&P 500, then the investor would likely purchase an index fund to gain the higher return, plus achieve immediate diversification of risk. Some research mainly focused on accuracy of earnings estimates which is not the same as the prediction of a TSP. A review of this past research is presented in chronological order.

In 1986 two articles appeared in the same issue of the Journal of Financial Economics. Rock (1986) "Why New Issues are Underpriced," found in some cases the offering firm priced new shares at a discount from their expected value to attract demand, especially from otherwise "uninformed" investors. He cited earlier studies by Ibbotson (1975) where the underpricing was around $11 \%$ and by Ibbotson 
and Jaffe (1975) where average excess returns of about 17\% occurred. [1] Regarding our research, this would seem to produce a high percentage of Buy recommendations on IPOs. We report our results later to answer this possibility.

The article by Beatty and Ritter (1986), "Investment Banking, Reputation, and the Underpricing of Initial Public Offerings," also discussed underpricing. They noted the greater the uncertainty about the expected value of an IPO, then the greater the underpricing of the IPO. [2] Thus, the two 1986 articles point to a prevalence of IPO underpricing.

O'Brien (1990) in "Forecast Accuracy of Individual Analysts in Nine Industries" focused on only one activity, earnings forecasting. She reviewed industries such as Paper and Allied Products (SIC 26), Primary Metal (SIC 33), and Insurance (SIC 63). A total of 422 analysts were graded on the accuracy of their Earnings per Share (EPS) forecast vs. the actual EPS. She did not find "...consistent differences in forecasting ability..." [3]

An article by Butler and Lang (1991), "The Forecast Accuracy of Individual Analysts: Evidence of Systematic Optimism and Pessimism" also reviewed only the accuracy of earnings forecasts. The results are very similar to O'Brien (1990) concluding "...Individual analysts show little evidence in forecast ability..." [4] In 1997, Mikhail, Walther, and Willis continued the focus on earnings forecasts in "Do Security Analysts Improve Their Performance with Experience?" We took a special interest in their findings because it asked a related question on whether forecasting accuracy improved the more time an analyst had spent on a specific company. They found a significant decrease in the earnings forecast error as the analyst gained experience in coverage of a specific company. The lowest error did not occur until after forty previous quarters of such coverage (i.e., more than ten years in firm specific experience). [5]

The same three authors addressed analyst turnover and earnings forecast accuracy in their 1999 article "Does Forecast Accuracy Matter to Security Analysts?" They found lower accuracy rates associated with higher turnover, in effect confirming the importance of experience and their 1997 results. [6]

As noted in these four studies, the research examined accuracy of an EPS forecast, not TSP. The TSP accuracy gained some prominence with a study released in 2010 by Bonini, Zanetti, Bianchini, and Salvi, "Target Price Accuracy in Equity Research." The stocks covered were traded on the Milan Stock Exchange, thus no exposure to stocks traded on U.S. Exchanges. They found forecasting accuracy (predicted vs. actual) as very limited with error rates of around 37\%. [7]

For specifically U.S. stocks and TSP accuracy, we turned to a 2013 study by Bradshaw, Brown, and Hung "Do Sell-Side Analysts Exhibit Differential Target Price Forecasting Ability?" The study tested whether the Actual Stock Price (ASP) met or exceeded the Target Stock Price (TSP) at least sometime within the twelve-month forecast horizon. For example, if the starting stock price is $\$ 40$ per share and the analyst estimated a TSP of $\$ 50$ per share within the next twelve months, a gain of $25 \%$ is achieved. If the ASP met or exceeded the TSP at least sometime within the next twelve months, then the analyst was graded as having an accurate TSP forecast and a gain of at least $25 \%$ was achieved. However, if the ASP was always $<\$ 50$ within the next twelve months, then it was considered an error because the ASP never met or exceeded the TSP and the $25 \%$ projected gain was never achieved. This study, and its large sample size of 492,647 from an average of 2,278 analysts per year over a decade of estimates, had important results. They found in $64 \%$ of the sample the ASP met or exceeded the TSP at least sometime within the twelve-month forecast horizon resulting in an accurate forecast rating. There was a lot of fluctuation in this accuracy rate during the ten-year period as shown in Figure 1. Note the lowest four years of accuracy were: $2000 @ 52 \%, 2001 @ 51 \%, 2002 @ 48 \%$, and $2008 @ 51 \%$, were all years where the return on the S\&P 500 was negative. [8]

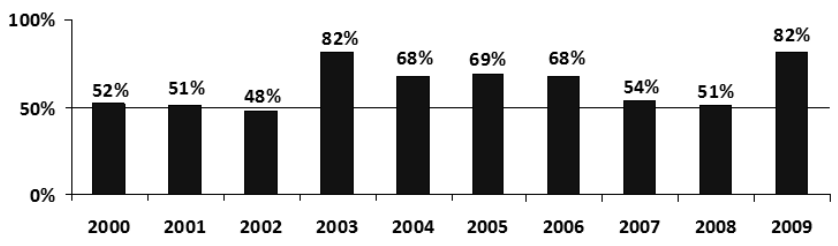

Figure 1. Annual forecast accuracy 2000-2009 average: 64\%( Source: Bradshaw, Brown, and Huang, December 2013.) 
In conclusion, we found some gaps in the previous research which we wanted to correct. First, no previous review of TSP accuracy has focused only on IPOs. We think this is important because setting a TSP for an IPO presents any analyst with unique challenges given not much, if any, track record. A Research Report and TSP for a company like General Electric (NYSE: GE) which went public in 1896, is going to have a much different financial background than a Research Report and TSP for an IPO like Zulily (NASDAQ: ZU), an online retailer, which went public in November 2013. Second, we were intrigued by the research of Mikhail, Walther, and Willis (1997) and their finding that a higher number of years of firm-specific experience for the analyst produced better TSP accuracy. With an IPO, no such experience could exist given the statement "...We are initiating coverage..." in a typical first Research Report on an IPO. However, we decided to examine if any of the analyst(s) writing the IPO Report had certification as a Chartered Financial Analyst $\left(\mathrm{CFA}^{\oplus}\right)$, considered the industry standard for those in the business of securities analysis. Does having a $\mathrm{CFA}^{\circledR}$ improve TSP accuracy? Third, we started this article noting the importance of accuracy in a TSP forecast. We decided to look at companies who issue Research Reports and their record for TSP accuracy on IPOs.

\section{Methodology}

The study individually examined a total of 692 Research Reports which initiated coverage that were issued on IPOs during 2013. We used the "Initiating Coverage" Report because it was the first one issued and then seen by investors who often make their decision close to the IPO date. Our source was Thomson ONE. Since the timeframe for a TSP forecast is normally twelve months, we compared the TSP forecast with the Actual Stock Price (ASP) for the following twelve months. If the ASP was greater than or equal to the TSP at least sometime during the twelve-month period, it was considered an accurate TSP forecast. This was the same methodology used by Bradshaw, Brown, and Huang in their 2013 study where the result was $64 \%$ accuracy (see Figure 1).

We also calculated the Mean Absolute Error (MAE) in the forecasts. This was also used in previous studies to determine the true error. We also sorted the data by $\mathrm{CFA}^{\oplus}$ versus Non-CFA for the analyst(s) writing the Research Report. If at least one of the analyst(s) was a $\mathrm{CFA}^{\oplus}$, then it was considered a $\mathrm{CFA}^{\circledR}$ report. This involved looking at each Research Report individually and the names of the authors with the assumption that if an analyst was a $\mathrm{CFA}^{\oplus}$, it would be indicated next to their name. The $\mathrm{CFA}^{\circledast}$ is regarded by many in finance as the key designation for investment professionals in such areas as research and the management of portfolios. We also sorted by the companies issuing the Research Reports (e.g., Morgan Stanley, Wells Fargo Securities, Barclays).

As an example of our methodology, let's take the Research Report for the IPO on Noodles \& Company (NASDAQ: NDLS) issued by Piper Jaffray initiating coverage on July 23, 2013. The IPO on NDLS was on June 28, 2013 at $\$ 18.00$ per share. The Research Report was written by Nicole Miller Regan and John C. Long, CFA ${ }^{\oplus}$, so it was classified as a CFA Report because at least one of the analyst(s) had the CFA ${ }^{\circledR}$ designation. The market price was $\$ 42.12$ on the July 23 Report and the TSP was forecasted at $\$ 48.00$ within the next twelve months or July 23, 2013 - July 23, 2014. The price of NDLS did hit a high of $\$ 48.30$ within that twelve month period, so the TSP was considered accurate as the ASP was $\geqslant$ TSP $(\$ 48.30 \geqslant \$ 48.00)$. The Mean Absolute Error (MAE) of ASP versus TSP of $\$ 48.30$ versus $\$ 48.00$ was $0.625 \%$. Thus, the analysts made a good TSP forecast for the IPO on NDLS.

\section{Results}

\subsection{Overall TSP Accuracy}

Table 1 reports the overall accuracy for the 692 IPO Research Reports. In this Table, we report the accuracy rate based on whether the ASP met or exceeded the TSP sometime within the twelve-month period. This was the same methodology used by Bradshaw, Brown, and Huang (2013) where they found the accuracy rate at $64 \%$.

Table 1. Overall Research Reports Accuracy on Initial Public Offerings (IPOs) Target Stock Price (TSP) 2013 2014. 


\begin{tabular}{c|c|c}
\hline Accurate & 482 & $69.65 \%$ \\
\hline Not Accurate & 210 & $30.35 \%$ \\
\hline Total & 692 & $100.00 \%$ \\
\hline
\end{tabular}

We found these IPO results rather surprising as the accuracy rate was higher at nearly $70 \%$ as compared to the $64 \%$ found by Bradshaw, Brown, Huang (2013). As we noted earlier, a Research Report and TSP on an IPO should be more difficult given the lack of much, if any, previous financial and securities data on the company. Granted, it is only one year of data, but we did not expect the $70 \%$ accuracy, we expected it to be less than $64 \%$.

\subsection{Accuracy: CFA® vs. Non-CFA®}

We breakdown the overall accuracy rates for the 692 Research Reports from Table 1 by CFA ${ }^{\circledR}$ vs. Non$\mathrm{CFA}^{\circledR}$ analyst(s) in Table 2.

Table 2. Research Reports Accuracy by CFA® vs. Non-CFA® on Initial Public Offerings (IPOs) Target Stock Price (TSP) 2013 - 2014.

\begin{tabular}{c|l|c|c|c|c|c}
\hline Category & \multicolumn{2}{|c|}{ Overall (Table 1) } & \multicolumn{2}{|c|}{ CFA $^{\circledR}$} & \multicolumn{2}{c}{ Non-CFA $^{\circledR}$} \\
\hline Accurate & 482 & $69.65 \%$ & $220^{*}$ & $71.20 \%$ & $262^{*}$ & $68.41 \%$ \\
\hline Not Accurate & 210 & $30.35 \%$ & $89^{*}$ & $28.80 \%$ & $121^{*}$ & $31.59 \%$ \\
\hline Total & 692 & $100.00 \%$ & 309 & $100.00 \%$ & 383 & $100.00 \%$ \\
\hline
\end{tabular}

*Chi-Square Test for Independence not significantly different: $\mathrm{p}=0.4274$.

The $\mathrm{CFA}^{\circledR}$ designation produced slightly higher accuracy: $71.20 \%$ vs. $68.41 \%$, although difference not significant $(\mathrm{p}>0.05)$. Slightly more than half $(383$ or $55 \%$ ) of all Research Reports were written by Non-CFA ${ }^{\circledR}$ analyst(s).

\subsection{Mean Absolute Errors: Overall and CFA® vs. Non-CF A®}

A more detailed summary of accuracy needs to focus on the Mean Absolute Error (MAE). A higher accuracy rate as measured in Table 2 does not provide the magnitude of the error or, in this case, the lower the Mean Absolute Error (MAE), then the higher the relative accuracy. Table 3 reports the respective MAE's.

Table 3. Research Reports Mean Absolute Error (MAE) by CFA® vs. Non-CFA® Initial Public Offerings (IPOs) Target Stock Price (TSP) 2013 - 2014.

\begin{tabular}{c|c|c|c|c|c|c}
\hline Category & \multicolumn{2}{|c|}{ Overall } & \multicolumn{2}{c|}{ CFA $^{\circledR}$} & \multicolumn{2}{c}{ Non-CFA $^{\oplus}$} \\
\hline MAE & $31.00 \%$ & $\mathrm{n}=692$ & $28.65 \%^{*}$ & $\mathrm{n}=309$ & $32.90 \%^{*}$ & $\mathrm{n}=383$ \\
\hline
\end{tabular}

*MAE's were not significantly different: $\mathrm{p}=0.7541$.

The CFA ${ }^{\circledR}$ Reports did show a slightly smaller MAE at $28.65 \%$. However, the difference from the Non$\mathrm{CFA}^{\circledR}$ MAE of $32.90 \%$ was not significant $(\mathrm{p}>0.05)$ using t-test for the hypothesized difference between two proportions.

\subsection{Mean Absolute Errors for Securities Firms}

Finally, we examined the average MAE for securities firms that issued at least twenty IPO Research Reports in 2013. Table 4 lists twelve securities firms ranked from the lowest MAE (most accurate) to the highest MAE (least accurate). These twelve firms alone comprised $67 \%$ or 461 of the 692 Research Reports issued. 
Table 4. Mean Absolute Error (MAE) Twelve Securities Firms Research Reports Accuracy on Initial Public Offerings (IPOs) Target Stock Price (TSP) 2013 - 2014.

\begin{tabular}{|c|c|c|c|}
\hline Rank & Firm & No. Research Reports & MAE \\
\hline 1 & Jefferies & 35 & $21.39 \%$ \\
\hline 2 & Deutsch Bank & 52 & $21.55 \%$ \\
\hline 3 & Barclays & 47 & $25.31 \%$ \\
\hline 4 & BMO Capital & 21 & $28.02 \%$ \\
\hline 5 & Morgan Stanley & 48 & $28.62 \%$ \\
\hline 6 & Piper Jaffray & 29 & $28.83 \%$ \\
\hline 7 & UBS Research & 28 & $28.86 \%$ \\
\hline 8 & Credit Suisse & 47 & $29.70 \%$ \\
\hline 9 & JP Morgan & 68 & $32.34 \%$ \\
\hline 10 & RBC Capital & 20 & $32.39 \%$ \\
\hline 11 & Wells Fargo Securities & 42 & $33.39 \%$ \\
\hline 12 & JMP Securities & 24 & $47.02 \%$ \\
\hline \multicolumn{2}{|r|}{ Total } & 461 & \\
\hline
\end{tabular}

\subsection{Type of IPO Recommendation: Buy, Sell, Hold}

We also decided to look at how many of these IPO recommendations were Buy, Sell, or Hold. Buy included designations such as Overweight, Outperform, etc. Sell included Underperform, Sector Underperform. Hold included Neutral, Equal-Weight, etc. The results were that $75 \%$ are Buy recommendations, 24\% Hold, and 1\% Sell. Given these are IPO's, a Hold means "wait and see" and a Sell means selling short the IPO or simply don't Buy the IPO. The high percentage of Buy recommendations is consistent with our discussion of Rock (1986).

\section{Conclusions}

Our research found an important gap in previous research on the TSP accuracy in Research Reports, especially regarding IPOs. To our knowledge, this is the first such study as we examined TSP accuracy on 692 Research Reports issued in 2013 on IPOs.

Nearly $70 \%$ of these 692 Research Reports had a TSP that was equal to or exceed by the ASP (Table 1). Thus, the expected gain (i.e., TSP) was achieved sometime during the twelve-month forecast period. This was greater than the comparable $64 \%$ for some 492,647 TSP forecasts found by Bradshaw, Brown, and Huang (2013) over a ten-year period. Surprisingly, the IPO accuracy rate was higher at nearly $70 \%$. Granted this comparison on accuracy rates is subject to different time periods and the possibility of IPO price supports. For CFA® reports, the accuracy rate was $71.20 \%$ vs. non-CFA® at $68.41 \%$ (Table 2 ). However, the difference was not significant using the Chi-Square Test for Independence.

When considering the Mean Absolute Error (MAE), it was 31.00\% for all 692 Reports. The MAE was $28.65 \%$ (more accurate) for those 309 Reports written by at least one CFA® and a slightly higher MAE $32.90 \%$ (less accurate) for the 383 Reports where no CFA® was involved in the TSP (Table 3). However, the difference in these MAE's was not significant when testing for the hypothesized difference between two proportions.

Finally, we looked at twelve securities firms who had written a Research Report on an IPO in 2013 (Table 4). They were ranked in order of lower MAE (most accurate) to higher MAE (less accurate). Jefferies had the lowest MAE at $21.39 \%$.

We think more research is needed on Research Report TSP accuracy, both all Reports issued and on IPOs, possibly annually. The more comparative analysis we see, the better investors can judge the accuracy of the firms and individuals who write these influential Research Reports. We think some important values and accountability can be added.

Acknowledgement. We thank Kenneth Leung of the University of Denver for his useful comments. 


\section{References}

1. Rock, K., 1986. "Why New Issues Are Underpriced." Journal of Financial Economics, Vol. 15, No. 1-2 (Jan/Feb 1986): $187-212$.

2. Beatty, R.P., and J. Ritter (1986). "Investment Banking, Reputation, and the Underpricing of Initial Public Offerings." Journal of Financial Economics, Vol. 15, No. 1-2 (Jan/Feb 1986): 213-232.

3. O'Brien, P., 1990. "Forecast Accuracy of Individual Analysts in Nine Industries." Journal of Accounting Research, Vol. 28, No. 2 (Autumn 1990): 286-304.

4. Butler, K., and L. Lang, 1991. "The Forecast Accuracy of Individual Analysts: Evidence of Systematic Optimism and Pessimism." Journal of Accounting Research, Vol. 29, No. 1 (Spring): 150-156.

5. Mikhail, M., B. Walther, and R. Willis, 1997. "Do Security Analysts Improve Their Performance with Experience?" Journal of Accounting Research, Vol. 35, Supplement 1997: 131-157.

6. Mikhail, M., B. Walther, and R. Willis, 1999. "Does Forecast Accuracy Matter to Security Analysts?" The Accounting Review, Vol. 74, No. 2 (April): 185-200.

7. Bonini, S., L. Zanetti, R. Bianchini, and A. Salvi. 2010. "Target Price Accuracy in Equity Research." Journal of Business Finance \& Accounting, Vol. 37, No. 9 and 10 (November/December): 1177-1217.

8. Bradshaw, M., L. Brown, and K. Huang, 2013. "Do Sell-Side Analysts Exhibit Differential Target Price Forecasting Ability?" Review of Accounting Studies, Vol. 18, No. 4 (December): 930-955. 